consciously, by operator or bystander, may lose rather than gain in force by repetition. This fact is in itself a weakness in the evidence.

Next, it nowhere appears, from Dr. Gamgee's account of the experiments which so fully convinced him of the action of magnets on sensation, that due precautions were taken to prevent the possibility of the patient's attention being in any way influenced by those around her, or even of a more obvious source of knowledge of the " magnetic" application. In no case, apparently, was the patient blind. folded; nor is it stated that perfect silence was observed by operator and spectators-two seemingly obvious and initial precautions towards excluding the influence of expectant attention, or even possible fraud. Even in the case of the blind patient (Case III) related in Dr. Gamgee's paper, her long residence of over thirty years in the hospital, coupled with the omission from the account given of all precautions against "leading" the patient being taken, renders the "experiment" far from conclusive, in spite of the statement of no effect following the application of the convex end of the magnet.

Again, while admitting freely the genuine return or disappearance of sensation on the application of a solenoid or the approximation of a magnet, it does not appear that exactly similar instruments, unendowed with magnetic or electrical power, were tried, as one attempt out of many similar ones to alter the conditions of and so to verify the experiment. Whether or not this precaution was taken by M. Charcot himself at the outset of his observations, it has clearly not contributed to Dr. Gamgee's convictions, as they appear stated in the paper under review.

Case v, quoted by Dr. Gamgee, describing the placing of a magnet at the distance of one-third of an inch from the patient's left temple, and the sequent phenomenon of vanishing achromatopsia, is a remarkable instance of inconsequent argument; no causal connection between the magnet and the result being even a plausible hypothesis in the absence of a comparative trial of other agents, and of the absolute certainty of the patient's ignorance as to what means, if any, were being employed to produce the result in question.

As a further instance of a rash arrival at important conclusions, I would quote Dr. Gamgee's statement regarding "ovarian hyperæsthesia". That a necessarily somewhat diffused pressure on an illdefined anatomical part, conveniently called the "region of the ovary", proves, when tenderness is evinced, that the ovary is hyperæsthetic, is apparently, in Dr. Gamgee's opinion, a sufficiently -accurate datum for the further conclusion of a necessary connection between ovarian disturbance and the phenomena of hystero-epilepsy. Such reasoniug may possibly be called in question by the anatomist or the unprejudiced and scientific gynæcologist. I leave it to others to express opinions on the practical advisability of the hasty introduction of prolonged abdominal palpation into the therapeutics of feminine nervous diseases.

Lastly, as a piece of internal evidence taken from Dr. Gamgee's own paper against the truth of the conclusions therein contained, I would call attention to the statement that no results were obtained by either M. Charcot or himself from the application of electro-magnets to frogs. On the hypothesis of a human mental factor being essential to the production of the phenomena in question, the insensibility of the batrachian nervous system to such influences becomes a va!uable "negative instance". in the inductive process.

Doubtless, as Dr. Gamgee says, an intimate connection between the study of physiology and clinical medicine is desirable in the interests of both sciences. Perhaps in England more than elsewhere this connection is kept up ; and thus the physiologist, being somewhat conversant with the infinite permutations and combinations of nervous and socalled "functional" phenomena in the human organism, is, as a rule, aware of the complexity of the matter in hand, when these phenomena become the subject of a scientific investigation, and recognises, as physicians strive to do, the necessity of applying the most rigorous methods of research before arriving at any conclusion in so difficult a field of observation. The reciprocal advantage to the practical physician of the knowledge gained from the researches of the physiologist requires no advocacy.

It would appear from the above considerations, bearing in mind the a priori unlikelihood of the alleged causation of the phenomena under discussion, and the bygone explosion of similar theories; no less than the fact of such explanations being gratuitous and unnecessary, that as yet Dr. Gamgee's opinion on "animal magnetism" is a conclusion drawn from very scanty data, and by no intelligible logical method. The importance, however, somewhat factitious though it may be, now given to this class of phenomena, renders some notice of the kind of arguments adduced in their support more than excusable.

\section{THE TREATMENT OF GENU VALGUM.}

\section{By H. A. R E E V E S, F.R.C.S.Ed.,}

Surgeon to the Royal Orthopædic Hospital; Assistant-Surgeon and Teacher of Practical Surgery at the London Hospital; etc.

Mr. VinCENT JACKSON's note in the JouRnaL of September 28th calls for a reply. But for his remarks, private and literary engagements - the latter, unfortunately, long unkept-would have stood in the way of my reverting to the suhjects of knock- and bow-knees for some weeks. I will first reply to Mr. Jackson, and then give my latest experience in the treatment of these deformities.

Mr. Jackson by implication raises the question of priority; but, if he will again read my lecture, he will see, first, that I said that the novelty of this my second method, which is suitable only for moderate cases of genu valgum, consists in the combination of the division of the biceps tendon, the ilio-tibial band, and the exterral lateral ligament, with immediate forcible straightening.

Secondly, Mr. Jackson says that in March of this year he divided the left biceps tendon and the adjacent tendinous structures completely. Mr. Jackson has wisely inserted the adverb, because any incomplete division would have been useless, and also because tendons, etc., are sometimes only transfixed and partially divided. "A few days afterwards," continues Mr. Jackson, "the knee was forcibly straightened ......, and the patient remained in the hospital for three or four months."

Now, in point of time, I preceded Mr. Jackson by more than three years; for, when the East London Children's Hospital was at Ratcliff Cross, I divided these three structures, but did not then attempt immediate forcible straightening, and only after three days had elapsed. The recent operation to which I referred in my lecture (which was sent to the JoURNAL about four months ago) was done a week after my first subcutaneous osteotomy of the internal femoral condyle in March of this year, and differs entirely not only from that which Mr. Jackson did, but is in direct opposition to the usual surgical teaching, which instructs us to let a tendon unite before stretching it. Mr. Jackson will, I am sure, pardon me if I say, and in no unfriendly spirit, that his remarks are somewhat vague. Let any one try to divide "adjacent ten:dinous structures", and he will find that, unless he seek for the external lateral ligament separately and independently, he will either not divide it at all or cut the peroneal nerve. The ilio-tibial band may be divided through the same puncture as that used for the biceps tendon-of course cutting outwards; but the seat of selection for tenotomy of the biceps tendon is high up in the outer boundary of the popliteal space, whereas, to really divide the external lateral ligament or ligaments, one must go lower down, passing the tenotome between the nerve and tendon, and cutting inwards; for to prick the joint-capsule subcutaneously is nothing to dividing the nerve. I have never seen the least mischief from thus dividing the ligament, although it would not be logical to conclude that the joint was never pricked. There is no necessity, however, if the operation be cautiously done, to interfere with the joint.

Mr. Jackson will excuse me for saying that, anatomically or histologically, I know of no "tendinous structures" adjacent to the biceps tendon; but, waiving this structural point, it would be well to know if he did as I did-i.e., point out to the bystanders what he meant to do, and naming and dividing each structure as he went on. Many of us have surgical after-thoughts, in which we think we also must have done so and so; but there is considerable difference between this and operating with "malice aforethought" and intent made plain. I do not say Mr. Jackson did not do all this; but, to make his oblique claim to priority clear, he must not only show this, but aiso that his first operation not only preceded mine, but was identical in its method. Of "modifications" we have no end.

The three or four months' stay in hospital after this operation, of which $\mathrm{Mr}$. Jackson sfeaks, is-other things being equal, or nearly soa great drawback to these tenotomy methods; and my experience during the last four months goes clearly to prove that osteotomy of the condyle combines the great desiderata of simplicity, safety, rapidity in execution and result, and efficacy.

I note that Mr. Jackson gave an anæsthetic on two occasions to his patient. This is another drawback. At the Royal Orthopredic Hospital, we do a large number of tenotomies weekly, and I have frequently operated on from seven to ten patients on a Monday, and never do we give an anæsthetic.

I would remind Mr. Jackson and other surgeons interested, that the external lateral ligament was divided by Langenbeck for this deformity over twenty years ago; but he did not attempt immediate forcib!e straightening, nor did he divide the ilio-tibial band. The recently 
revived operation of dividing the shaft of the femur for genu valgum was also done many years ago by Langenbeck, Meyer, and Bauer, and then dropped. I mentioned this to my class, and gave the reasons which led to the operation being abandoned; but in my published lec. ture, to avoid being prolix, I did not allude to it, because, in these busy days, one must be charitable enough to credit even the surgeon who would be deemed the most practical with a moderately competent knowledge of surgical history and literature, English and foreign.

I gladly now fill up one or two gaps in my lecture. Mr. Annandale's operation of opening the joint and sawing off the internal condyle on a level with the outer was mentioned to the class; but I did not state that Mr. Chiene of Edinburgh had preceded Dr. Macewen in semoving a wedge-shaped piece from the inner condyle. If the reports of the meetings of German surgeons during the last two or three years be looked up, I think it will be found that these operations, or some very like them, have been previously done abroad.

With reference to osteotomy of the femoral shaft, I would just say thint Mr. Bradley of Manchester, in a paper read at the recent meeting of the Association, condemrs it, and recommerds the methcd of Dr. $\mathrm{O}$-ston, which, to my mind, is a much more severe, though certainly, in bad cases, a more radical method.

On another occasion, I hope to discuss the pathology of knock- and bow-knees, and the reasons pro and con. the various operations; but nuww I will merely say that my objections to osteotomy of the femora shaft are based on the following facts. 1. In severe cases, it is not enough. One must do as Mr. Barwell did-i.c., divide the tibia and fibula six or seven weeks afterwards. 2. It takes (in severe cases) very much longer than loosening of the inner or outer condyle, as the case may be, before the patient is cured. About four mon!hs would be a rapid convalescence, whereas the patients may be safely discharged in from four to five weeks in most cases operatei on by my method. 3 . 'There is the risk of non-union and necrosis. 4. The suprapatellar pouch of the synovial membrane may be torn, or inflammation may exiend to it. 5. To divide three hones when you can remedy the deformity by simply loosening part of one is not surgical justice to the patient. 6. Another strong objection to division of the femoral shaft is the fact, that passive motion cannot be safely commenced under six weeks. I now discharge patients in that time. Perhaps No. 4 may be left out of consideration, as extended experience has shown that the proximity of my chisel-cut to the joint-surface is not, as some anticipated, almost certain to lead to synovitis. I have now done fourteen condyles, and never have I had synovitis. In two of my early cases, in which the rickety condyles were much softer than I anticipated, the chisel entered the joint, and there was slight temporary effusion, but nothing more. In another case, in which the joint was entered through the chisel not being sufficiently withdrawn by the dresser while I was straightening the limb, there was not the slightest effusion or pain in the knee, or rise of pulse or temperature after the operation.

I commence passive motion much earlier than I did fuur months ago. Three weeks since, I operated simultaneously on both knees of two cases of severe double genu extrorsum and one of severe left valgum, and fourteen days afterwards we found that the patients could, voluntarily and without using their hands to the limbs, hend the joints to semiffexion. Passive motion was then resorted to, and is being done more and more daily; and, on my visit to the hospital to-day, just three weeks and two days after the operations, the patients could walk with the slight support of my hand. I allowed this simply to test what they were capable of, and shall continue gentle walking exercise for them every day. I am sure they would have been able to walk much better had I allowed them to get about sooner, and that the weakness of the limbs was not due so much to the result of the operation as to tire enforced confinement of the limbs. We all know that even a healthy joint, immovably fixed for a fortnight or three weeks, will become stiff and weak.

I have not in my last three or four cases used the splint of which I spoke in my lecture, but have put up the limbs in plaster of Paris. The small wound will take care of itself. I have always found it healed on removing the bandage. As a precautionary measure, I apply an icebag over the knee; but this is not essential. In future, I shall let my paiients get about on crutches after the first week.

I believe I was the first to point out that in most cases of genu varum or extrorsum, and cerlainly in all the rickety ones which $I$ have seen, the external condyle is much overgrown, and the joint-surface is ob!ique from within down and out; in fact, just the opposite condition obtains to that which is present in genu valgum. In the two cases of extreme genu extrorsum of which I have just spoken, I completely remedied the deformity, as far as the knee is concerned, by loosening the outer condyle and forcibly straightening. I say straightening, but in practice I always over-correct the deformity and produce a slight valgum in extrorsum cases, and vice vers $a$, and then put them up straight. If the femur be much curved -a common condition in rickety cases-the knees will be straightened and an inch or two added to the patient's height; but of course the femur will remain curved. The test of the efficacy of the operation is the measurement between the knew in extrorsum cases before and after the operation, and between the feet in valgum cases. In both these cases, the lower two thirds of the femur were curvel, and division of the lower end would have been not simply useless, but really mischievous.

To return to Mr. Jackson: he has long been known to me by repute (through a pupil of mine who was formerly a pupil at the Wolverhampton Hospital) as an active-minded surgeon, always anxious to adopt, without prejudice, anything new or old which promised well for his patients. I had personal proof of this when he wrote me, asking where he could procure my urethro-cystoscope. Although I have never heard so from him, I am quite certain that he, in common with all those who have tried that simple instrument, must speak in its favour ; and I am just as sure that, if he will try my method of osteotomy in kncck-or bow-knees, he will be as satisfied with it as I am and those who have seen the operation and its results. I m2y, perhaps, be allowed to add that Professor Annandale of Edinburgh practised my operation about a fortnight after an account of it first appeared in the JUURNAL, and that he wrote me on tro occasions expressing his entire satisfaction with it. A surgeon now in London saw him operate, and told me of the excellent position in which he got the limb. Professor Annandale operated with the limb extended; I always bend the limb to render the condyles prominent, diaw down the suprapatellar pouch of the synovial membrane, and have the ley and thigh well steadied by assistants.

I take this opportunity of thanking several London and provincial surgeons for having sent me some very interesting cases, and to assure thein that my complete results shall be made known in due course.

Mr. Jackson agrees with the remarks in my lecture as to the impropriety of claiming successes before they are obtained. I said in my paper, and now I would emphasise my observation, as it does not seem to have been grasped in some quarters, simple enough though the remark be: "The immediate results are very good, and I have no doubt the later ones will be equally satisfactory."

\section{REMARKS ON THE USE AND VALUE OF THE LONG FORCEPS.}

By THOMAS RADFORD, M.D., Manchester.

According to the opinion of Dr. Swayne (Journal, page 459), the obstetric forceps are more frequently used in cases of difficult labours, at the present time, than they were in times gone by; and there is no doubt that a judicious management of this process, and a timely and appropriate application of the forceps, contributes very greatly to a propitious termination of the labour. He, however, talies a very unfavourable view as to the saving of infantile life. He states that he agrees with the opinion of Dr. Galabin, who says: "It has not been shown that the majority, or any considerable proportion, of the stillbirths which now occur in Britain would be preventable by a more timely resort to forceps." (See Obstetrical Fournal, vol. v, page 586.) To what practical purpose will such a conclusion lead ? Is it meant that, so far as infantile life is concerned, it would be the most safe to trust the issue of the labour to the natural efforts? Can statistics, which embrace such various and different particulars, lead to a true deduction? For my part, I do not fear to declare that I think it is quite impossible to come, from them, to a right conclusion as to infantile mortality.

If the practice of the Rotunda Lying-in Hospital, Dublin, during the mastership of the late Dr. Collins, be compared with that which has since been adopted, it will be found that there has been an immense saving of infantile life by the early and more frequent use of the forceps -thercby superseding the prevailing practice of the destructive operation of craniotomy.

From 1842 , Dr. Swayne used the forcers in one hundred and sixtythree cases ; but he excluded ten cases from his calculation which were complicated with convulsions, haemorrhage, and prolapsus of the funis, and therefore attended with special danger, so that there remained for his computation one hundred and fifty-three cases, in which the forceps were used on account of want of uterine power, or want of room in the pelvis. Of these, ninety-two were consultation cases, and sixty-one were attended by Dr. Swayne himself. The infantile mortality in the one hundred and fifty-three cases was twenty-three still-births, of which all 